\title{
Het co-assistentschap sociale geneeskunde aan het VU medisch centrum in relatie tot het Raamplan 1994
}

\author{
M.B.M. Soethout, G. van der Wal, W. van Mechelen
}

\begin{abstract}
Samenvatting
Inleiding: In januari 2000 is een herzien co-assistentschap sociale geneeskunde aan het VU medisch centrum te Amsterdam ingevoerd, geënt op het Raamplan 1994. Om na te gaan in hoeverre de sociaal-geneeskundige eindtermen van het Raamplan in het oude en herziene coassistentschap aan de orde kwamen, is onderzoek verricht onder co-assistenten die het oude of herziene co-assistentschap sociale geneeskunde hebben doorlopen.
\end{abstract}

Methode: Na afloop van zowel het oude als het herziene co-assistentschap is aan studenten gevraagd in hoeverre ze een aantal algemene eindtermen beheersten die in het Raamplan 1994 toebedeeld zijn aan de discipline sociale geneeskunde. Tevens is nagegaan welke sociaal-geneeskundige problemen de studenten hebben gezien en in welke mate zij disciplinegebonden vaardigheden hebben geoefend.

Resultaten: In het herziene co-assistentschap is het gerapporteerde beheersingsniveau van de algemene eindtermen significant verbeterd ten opzichte van het oude co-assistentschap. Van de problemen, gelieerd aan de sociale geneeskunde, komt in het oude en in het herziene co-assistentschap ongeveer de helft aan de orde. Vaardigheden worden in het herziene co-assistentschap in tegenstelling tot het oude co-assistentschap op voldoende niveau geoefend.

Conclusie: Een herziening van het co-assistentschap sociale geneeskunde heeft geleid tot een hoger beheersingsniveau van algemene eindtermen en meer expliciete aandacht voor problemen toegewezen aan de sociale geneeskunde. De grootste winst wordt bereikt met het oefenen van sociaal-geneeskundige vaardigheden. Deze worden alle ruim voldoende geoefend. (Soethout MBM, Wal G van der, Mechelen W van. Het co-assistentschap sociale geneeskunde aan het VU medisch centrum in relatie tot het Raamplan 1994. Tijdschrift voor Medisch Onderwijs 2001;20(6):248-256.)

\section{Inleiding}

In het kader van een herziening van de coassistentschappen van het VU medisch centrum (VUmc) te Amsterdam zijn vanaf januari 2000 de algemene eindtermen en problemen van Raamplan 1994 expliciet toebedeeld aan bepaalde co-assistentschappen. ${ }^{1} 2$ Door de invoering van nieuwe elementen, onder andere een oudste co-assistentschap en stageoverstijgend onderwijs (SOO), was het noodzakelijk een aantal co-assistentschappen in te korten. Het co-assistentschap sociale geneeskunde, dat geprogrammeerd is aan het eind van het zesde studiejaar, is teruggebracht van drie naar twee weken. Het co- assistentschap is gericht op relevante eindtermen uit Raamplan 1994. De twee belangrijkste inhoudelijke verschillen met het oude co-assistentschap zijn een gerichte eendaagse voorbereiding aan het begin van het co-assistentschap en een facultaire terugkomdag ter afsluiting. Tijdens de voorbereiding wordt aandacht besteed aan de twee sociaal-geneeskundige hoofdstromen en tijdens de afsluiting verzorgt de co-assistent een presentatie voor medestudenten. De presentatie duurt circa vijftien minuten en behandelt een sociaal-geneeskundig probleem op het terrein waarin de praktijkstage is doorgebracht. 
Tabel 1. Vorm en inhoud van het oude en nieuwe co-assistentschap sociale geneeskunde van het VUmc.

\begin{tabular}{lll}
\hline & Oud co-assistentschap & Nieuw co-assistentschap \\
\hline $\begin{array}{ll}\text { Duur } \\
\text { Doelen }\end{array}$ & 3 weken & 2 weken \\
& Bepaald door sociaal- & Gebaseerd op Raamplan 1994 \\
geneeskundige instelling & \\
& 14.5 dagen praktijkstage & Centrale introductiedag \\
& 0.5 dag centrale afsluiting & 8 dagen praktijkstage \\
& & Zelfstandig oefenen van vaardigheden \\
& & Centrale afsluitingsdag \\
& & Eindpresentatie sociaal-geneeskundig probleem \\
Participerende & Arbodienst & Arbodienst \\
instellingen & UVI (bij arbostage) & UVI (afzonderlijke stage) \\
& GGD & GGD \\
& & Thuiszorginstelling (ouder en kindzorg)
\end{tabular}

Elementen uit de aan de sociale geneeskunde toebedeelde algemene eindtermen moeten in deze presentatie aan de orde komen, onder andere preventieve en collectieve aspecten. Circa $60 \%$ van de co-assistenten brengt een praktijkstage door bij een arbodienst, $30 \%$ bij een instelling van de Gemeentelijke Geneeskundige Dienst (GGD) en 10\% bij een uitvoeringsinstelling voor de sociale zekerheid (UVI) of thuiszorginstelling (ouder en kindzorg). Op jaarbasis worden zestien tot achttien groepen van twaalf tot zestien co-assistenten geroosterd. In alle groepen komen de diverse sociaal-geneeskundige terreinen als praktijkstage aan de orde, waardoor de eindpresentaties een representatief overzicht van sociaal-geneeskundige problemen vormen.

Om na te gaan in hoeverre de eindtermen van Raamplan 1994 in het oude en in het herziene co-assistentschap ook werkelijk aan de orde kwamen, is onderzoek verricht onder co-assistenten die het oude of het herziene co-assistentschap sociale geneeskunde hebben doorlopen. Hierbij is nagegaan (1) in welke mate de algemene eindtermen in het co-assistentschap aan de orde kwamen, (2) in hoeverre co-assistenten in aanraking kwamen met sociaal- geneeskundige problemen en (3) of de sociaal-geneeskundige vaardigheden voldoende werden geoefend.

In het kader van de herziening van de coassistentschappen is de problemenlijst van Raamplan 1994 geclusterd tot een hanteerbare omvang en is aan de algemene eindtermen een beheersingsniveau toegevoegd. ${ }^{3}$ Vervolgens is in overleg met het beroepsveld nagegaan welke algemene eindtermen en problemen expliciet in het co-assistentschap sociale geneeskunde aan de orde moeten komen, rekening houdend met de twee sociaal-geneeskundige hoofdstromen Arbeid en Gezondheid (bedrijfsgezondheidszorg plus verzekeringsgeneeskunde) en Maatschappij en Gezondheid (algemene gezondheidszorg plus jeugdgezondheidszorg). Tevens zijn de sociaal-geneeskundige vaardigheden geclusterd tot kernvaardigheden, die in de praktijkstage enkele malen onder supervisie geoefend moeten worden op niveau 3 van Raamplan 1994. In het nieuwe co-assistentschap moet de co-assistent de geziene problemen en vaardigheden bijhouden in een logboek. ${ }^{5}$

\section{Methode}

In 1999 en 2000 werd bij de afsluitende bijeenkomst van het oude, respectievelijk 
herziene co-assistentschap bij elke groep co-assistenten een vragenlijst afgenomen. De vragen hadden betrekking op de algemene eindtermen, problemen en vaardigheden. Voor het herziene co-assistentschap in 2000 had de vragenlijst alleen betrekking op de algemene eindtermen. De problemen en vaardigheden werden geïnventariseerd aan de hand van de logboekgegevens. De co-assistenten werd gevraagd om op een vijfpuntsschaal ( 1 = beheerst niet; 5 = beheerst routine in het uitvoeren) aan te geven in hoeverre zij zich thans bekwaam achtten met betrekking tot de algemene eindtermen. Bij de problemen werd gevraagd of het probleem tijdens het co-assistentschap aan de orde was geweest ('ja' of 'nee'). Bij de vaardigheden werd gevraagd of de vaardig- heid onder supervisie was geoefend ('ja' of 'nee'). De vragenlijst werd anoniem ingevuld.

Bij de algemene eindtermen werden gemiddelde scores berekend en werden groepsverschillen getoetst (t-toets). De mate waarin studenten met problemen geconfronteerd waren en het al of niet voldoende geoefend hebben van de vaardigheden zijn uitgedrukt in percentages.

\section{Resultaten}

De respons op de diverse vragenlijsten varieerde van $82 \%$ tot $100 \%$. De co-assistenten gaven in 2000 aan de algemene eindtermen beter te beheersen dan de co-assistenten in 1999 (tabel 2). Het gewenste eindniveau werd echter bij vrijwel geen van de sociaal-geneeskundige eind-

Tabel 2. Beoogd en door studenten gerapporteerd beheersingsniveau van algemene eindtermen na het co-assistentschap sociale geneeskunde VUmc op basis van het Raamplan 1994. Weergegeven zijn het gemiddelde (Gem.), de standaarddeviatie (Sd.) en eventuele significantie van het verschil tussen beide jaren.

\begin{tabular}{|c|c|c|c|}
\hline \multirow[t]{6}{*}{ Algemene eindtermen } & \multicolumn{3}{|c|}{ Beheersingsniveau $(1 \mathrm{t} / \mathrm{m} \mathrm{5})^{1}$} \\
\hline & \multirow[t]{5}{*}{ Beoogd } & \multicolumn{2}{|l|}{ Gerapporteerd } \\
\hline & & 1999 & 2000 \\
\hline & & Respons $87 \%$ & Respons $82 \%$ \\
\hline & & $N=87$ & $N=111$ \\
\hline & & Gem. (Sd.) & Gem. (Sd.) \\
\hline \multicolumn{4}{|l|}{ Medische aspecten } \\
\hline Proces van probleemoplossen & 5 & $3.2(0.7)$ & $3.5(0.8)^{*}$ \\
\hline Adviseren en voorlichten & 4 & $3.1(0.8)$ & $3.4(0.8)^{*}$ \\
\hline Verwijzen en consulteren & 4 & $2.7(0.9)$ & $3.7(1.0)^{* *}$ \\
\hline Begeleiding & $3-4$ & $3.0(0.8)$ & $3.2(0.8)$ \\
\hline Preventie & $3-4$ & $3.0(0.8)$ & $3.1(0.8)$ \\
\hline \multicolumn{4}{|l|}{ Wetenschappelijke aspecten } \\
\hline Bevorderen en onderhouden vakbekwaamheid & $3-4$ & $3.1(1.2)$ & $3.9(1.1)^{* *}$ \\
\hline \multicolumn{4}{|c|}{ Aspecten m.b.t. maatschappij en gezondheidszorgsysteem } \\
\hline Structuur en functioneren gezondheidszorg & 4 & $2.7(0.8)$ & $2.9(0.8)$ \\
\hline Wettelijke voorschriften & $4-5$ & $2.8(1.1)$ & $3.0(1.1)$ \\
\hline Financiering gezondheidszorg & 3 & $2.2(0.9)$ & $2.4(0.9)$ \\
\hline
\end{tabular}

1 beheersingsniveaus: $1=$ beheerst niet; 2 =alleen theorie bekend; $3=$ gezien tijdens co-assistentschap; $4=$ enkele malen onder supervisie zelf uitgevoerd; $5=$ beheerst routine in het uivoeren. ${ }^{*} \mathrm{p}<0.01 ;{ }^{* *} \mathrm{p}<0.001$. 
Tabel 3. Percentage studenten dat verschillende sociaal-geneeskundige problemen ziet tijdens de praktijkstage van het co-assistentschap sociale geneeskunde VUmc in 1999 en 2000. Voor 2000 wordt zowel het totaalpercentage gegeven als percentages uitgesplitst naar de hoofdstroom van de praktijkstage, 'arbeid en gezondheid' ( $A$ en $G$ ) en 'maatschappij en gezondheid' ( $M$ en $G$ ).

\begin{tabular}{|c|c|c|c|c|}
\hline \multirow[b]{3}{*}{ Problemen } & \multicolumn{4}{|c|}{ Percentage studenten } \\
\hline & \multirow{2}{*}{$\begin{array}{l}1999 \\
\text { Respons } 84 \% \\
N=207\end{array}$} & \multicolumn{3}{|c|}{$\begin{array}{l}2000 \\
\text { Respons } 85 \% \\
N=116\end{array}$} \\
\hline & & Allen & $\begin{array}{l}A \text { en } G \\
N=69\end{array}$ & $\begin{array}{l}M \text { en } G \\
N=47\end{array}$ \\
\hline Voedingsstoornissen zuigeling & 14 & 23 & 1 & 55 \\
\hline Problemen groei/ontwikkeling & 22 & 35 & 9 & 72 \\
\hline Gewichtstoename & 26 & 42 & 28 & 64 \\
\hline Spraak- en taalproblemen & 28 & 39 & 9 & 83 \\
\hline Eczemen & 29 & 29 & 14 & 51 \\
\hline Slechthorendheid & 39 & 45 & 25 & 74 \\
\hline Verminderde gezichtsscherpte & 39 & 37 & 29 & 49 \\
\hline Sociaal-culturele problemen & 41 & 52 & 33 & 79 \\
\hline Overige sociale problemen & 44 & 55 & 64 & 43 \\
\hline Onverklaarbare lich. klachten & 45 & 69 & 70 & 68 \\
\hline Gevolgen van chronische ziekte & 47 & 56 & 67 & 40 \\
\hline Problematisch middelengebruik & 49 & 52 & 45 & 62 \\
\hline Lichamelijke handicaps & 55 & 52 & 57 & 45 \\
\hline Werkproblemen & 66 & 67 & 97 & 22 \\
\hline Relatie- en gezinsproblemen & 69 & 63 & 51 & 81 \\
\hline Rugproblemen & 74 & 83 & 96 & 64 \\
\hline Stress & 79 & 79 & 96 & 55 \\
\hline Alle problemen tezamen per student & 45 & 52 & 47 & 59 \\
\hline
\end{tabular}

termen gehaald. Alleen de eindterm 'bevorderen en onderhouden van vakbekwaamheid' bereikte in 2000 het gewenste niveau. De beheersing van 'verwijzen en consulteren' nam het meest toe (van gemiddeld 2.7 in 1999 naar 3.7 in 2000; $\mathrm{p}<0.001)$. De eindtermen die bijzondere aandacht dienden te krijgen in het co-assistentschap ('preventie' en 'maatschappij en het gezondheidszorgsysteem') haalden met gemiddeld 3.1 en 2.9 niet het gewenste niveau van respectievelijk 3-4 en 4 . Dit laatste gold met name voor de subonderdelen 'structuur en functioneren van de gezondheidszorg', 'aangifteplicht be- smettelijke ziekten', 'medische aansprakelijkheid', 'klacht en tuchtrecht' en 'wet op de lijkbezorging'. De eindtermen 'methodes van opsporing van risicopatiënten' en 'vormen van preventie' bleken hoger te scoren (doch niet significant) bij co-assistenten die de praktijkstage in de hoofdstroom Maatschappij en Gezondheid hadden doorlopen in vergelijking met de co-assistenten die deelnamen aan de praktijkstage in de hoofdstroom Arbeid en Gezondheid. Het omgekeerde gold voor de eindtermen die betrekking hadden op 'medische keuringen' en 'ziektekosten en sociaal verzekeringsstelsel'. 
Tabel 3 laat zien dat in 1999 en 2000 ongeveer de helft van het totale aantal sociaalgeneeskundige problemen door een co-assistent werd gezien tijdens de praktijkstage. Indien de beide hoofdstromen afzonderlijk worden bezien, blijken er grote verschillen te bestaan. In 2000 kwamen in de hoofdstroom Arbeid en Gezondheid in vergelijking tot de hoofdstroom Maatschappij en Gezondheid met name 'werkproblemen', 'rugproblemen' en 'stress' aan de orde. In de hoofdstroom Maatschappij en Gezondheid werden studenten met name geconfronteerd met 'spraak- en taalproblemen', 'relatie- en gezinsproblemen' en 'sociaal-culturele problemen'. 1999 liet een overeenkomstig beeld zien. Indien gecorrigeerd wordt voor de sociaal-geneeskundige hoofdstroom waarin de praktijkstage werd doorlopen (65\% Arbeid en Gezondheid en 35\% Maatschappij en Gezondheid) bleek dat in 2000 'rugproblemen' en 'stress' door de co-assistenten het meest gezien werden. 'Voedingsstoornissen van de zuigeling' kwamen het minst aan de orde. Indien beide jaren worden vergeleken, lijken de individuele co-assistenten in 2000 met meer problemen in aanraking te zijn gekomen tijdens de praktijkstage van het co-assistentschap.

In het herziene co-assistentschap komt ook een deel van de problemen tijdens de groepsgewijze eindpresentaties aan de orde, zodat iedere co-assistent in korte tijd met een relatief groot aantal problemen gemiddeld $41 \%$ van alle problemen - in aanraking kwam. 'Rugproblemen' kwamen met $73 \%$ het meest aan de orde, gevolgd door 'onverklaarbare lichamelijke klachten' (67\%) en 'stress' (67\%). 'Eczemen' en 'verminderde gezichtsscherpte' scoorden met $0 \%$ en $7 \%$ het laagst.

Tabel 4 laat zien dat de vaardigheden in de praktijkstage van het herziene co-assistentschap in voldoende mate werden ge- oefend. Het laagst scoorden de vaardigheden die samenhangen met 'infectieziekten' tijdens de praktijkstage Algemene Gezondheidszorg. In de andere takken werden nagenoeg alle genoemde vaardigheden in $100 \%$ van de gevallen in voldoende mate geoefend. Ten opzichte van 1999 is er in 2000 een duidelijke toename in het onder supervisie oefenen van sociaal-geneeskundige vaardigheden.

\section{Conclusies en discussie}

Uit eerder onderzoek is bekend dat in coassistentschappen weinig gestructureerd aandacht wordt besteed aan de algemene eindtermen. ${ }^{6}$ In het nieuwe co-assistentschap sociale geneeskunde is dit deels ondervangen door de algemene eindtermen te operationaliseren tot concrete richtlijnen voor een eindpresentatie, zodat verwacht mag worden dat alle co-assistenten hier in meerdere of mindere mate mee in aanraking zullen komen.

Het nieuwe co-assistentschap sociale geneeskunde is ingevoerd vóór de herziening van de andere co-assistentschappen. Een vergelijking met het oude programma toont aan dat het herziene co-assistentschap sociale geneeskunde bijdraagt aan de implementatie van de algemene eindtermen van het Raamplan 1994. Door de geringe omvang van het coassistentschap sociale geneeskunde is deze bijdrage evenwel nog beperkt. De eindtermen worden nog niet voldoende bereikt. Hoewel de algemene eindtermen ook in andere co-assistentschappen aan de orde komen, is niet te verwachten dat het gewenste niveau alsnog in de resterende co-assistentschappen zal worden gehaald. Sociale geneeskunde is immers een van de laatste co-assistentschappen.

Algemene eindtermen die expliciet in het co-assistentschap sociale geneeskunde aan de orde horen te komen, scoren beneden het gewenste niveau. Dit geldt met 
name voor 'structuur en functioneren gezondheidszorg', 'aangifteplicht besmettelijke ziekten', 'wet op de lijkbezorging, 'medische aansprakelijkheid' en 'klacht en tuchtrecht'. De laatste twee betreffen het gezondheidsrecht. Dat wordt vaak tot de sociale geneeskunde gerekend, maar behoort in de regel niet tot de directe werkzaamheden van de sociaal-geneeskundige. De overige algemene eindtermen hebben slechts betrekking op een klein deel van de sociaal-geneeskundige beroepspraktijk (bijvoorbeeld infectieziekte- bestrijding als onderdeel van de algemene gezondheidszorg). Het is niet te verwachten dat co-assistenten hier in de praktijkstage voldoende mee in aanraking komen, noch dat dit met eindpresentaties is te corrigeren.

Het VUmc heeft als doelstelling dat tweederde van de problemen gezien wordt in een direct patiëntencontact. De overige problemen dienen indirect, bijvoorbeeld in groepsgewijze bijeenkomsten, aan de orde te komen. ${ }^{3}$ In het co-assistentschap sociale geneeskunde komt de individuele

Tabel 4. Aantal studenten dat per soort praktijkstage rapporteert ten minste enkele malen onder supervisie een vaardigheid geoefend te hebben in 1999 en 2000. De respons op de vragenlijst wordt per praktijkstage weergegeven.

\begin{tabular}{|c|c|c|}
\hline \multirow[t]{2}{*}{ Vaardigheden } & \multicolumn{2}{|c|}{ Aantal studenten } \\
\hline & 1999 & 2000 \\
\hline Algemene Gezondheidszorg (AGZ) & $\begin{array}{l}\text { Respons } 100 \% \\
N=65\end{array}$ & $\begin{array}{l}\text { Respons } 100 \% \\
N=12\end{array}$ \\
\hline $\begin{array}{l}\text { Medische indicatiestelling voor } \\
\text { huisvesting/voorziening of verstrekking } \\
\text { Registratie, voorlichting, maatregelen ter } \\
\text { voorkoming verdere besmetting infectieziekte } \\
\text { Geven van advies en/of voorlichting }\end{array}$ & $\begin{array}{l}16 \\
21\end{array}$ & $\begin{array}{l}8 \\
9\end{array}$ \\
\hline Jeugdgezondheidszorg (JGZ) & $\begin{array}{l}\text { Respons } 100 \% \\
N=65\end{array}$ & $\begin{array}{l}\text { Respons } 95 \% \\
N=41\end{array}$ \\
\hline $\begin{array}{l}\text { PGO van kinderen uit verschillende (leer)jaren } \\
\text { en registratie van de gegevens } \\
\text { Herkennen van riskant gedrag en leefstijlen } \\
\text { Geven van advies en/of voorlichting }\end{array}$ & $\begin{array}{l}27 \\
21 \\
25\end{array}$ & $\begin{array}{l}41 \\
41 \\
34\end{array}$ \\
\hline Bedrijfsgezondheidszorg (ARBO & $\begin{array}{l}\text { Respons } 85 \% \\
N=124\end{array}$ & $\begin{array}{l}\text { Respons } 80 \% \\
N=59\end{array}$ \\
\hline $\begin{array}{l}\text { (Aanstellings)keuring } \\
\text { Begeleiding bij ziekteverzuim } \\
\text { Geven van advies en/of informatie opvragen }\end{array}$ & $\begin{array}{l}54 \\
58 \\
44\end{array}$ & $\begin{array}{l}44 \\
59 \\
54\end{array}$ \\
\hline Verzekeringsgeneeskunde (UVI) & $\begin{array}{l}\text { Respons } 92 \% \\
N=12\end{array}$ & $\begin{array}{l}\text { Respons } 100 \% \\
N=11\end{array}$ \\
\hline $\begin{array}{l}\text { Beoordeling belastbaarheid } \\
\text { Invullen belastbaarheidsprofiel } \\
\text { Informatie opvragen }\end{array}$ & $\begin{array}{l}4 \\
5 \\
3\end{array}$ & $\begin{array}{l}11 \\
11 \\
11\end{array}$ \\
\hline
\end{tabular}


co-assistent met circa de helft van de problemen in aanraking tijdens de praktijkstage en met $40 \%$ van de problemen tijdens de groepsgewijze afsluitende bijeenkomsten. Omdat de inventarisatie van deze problemen op twee aggregatieniveaus heeft plaatsgevonden (individueel en groepsniveau), kunnen de percentages niet worden samengevoegd. Door de coassistent wordt één probleem uitgewerkt tot een eindpresentatie voor de gehele groep, zodat er wel een grote overlap van geziene problemen ontstaat. Al met al wordt de facultaire doelstelling voor de discipline sociale geneeskunde niet gehaald. Wel valt het gerealiseerde resultaat binnen de range die bij andere co-assistentschappen is gevonden. ${ }^{7}$

Dat in het nieuwe co-assistentschap meer problemen aan de orde komen, kan wellicht verklaard worden door het gebruik van een logboek. Hierdoor worden de problemen immers expliciet onder de aandacht gebracht. Er kan echter ook sprake zijn van een registratie-artefact doordat co-assistenten in het logboek gedurende hun stage de geziene problemen direct moeten aankruisen. Bij het oude co-assistentschap werd met behulp van een vragenlijst pas achteraf nagegaan of het betreffende probleem was gezien. Het logboek kan tot een grotere registratie hebben geleid. Desondanks wordt het aantal gewenste probleemcontacten niet gehaald. De beperkte duur van het co-assistentschap, de grote diversiteit in het vakgebied en de individuele invulling zijn hier mede debet aan. Door de groepsgewijze eindpresentaties van problemen wordt in het nieuwe co-assistentschap deels aan dit tekort tegemoet gekomen.

Met de herziene opzet van het co-assistentschap sociale geneeskunde is een duidelijke plaats ingeruimd voor het oefenen van sociaal-geneeskundige vaardigheden. Zo vormt de vaardigheid 'advisering en voorlichting' een structureel onderdeel van het herziene co-assistentschap, hetgeen de toename in expertise verklaart.

Met de invoering van het herziene co-assistentschap worden de algemene eindtermen beter bereikt dan in het oude co-assistentschap. Ook komen sociaal-geneeskundige problemen vaker aan de orde en worden sociaal-geneeskundige vaardigheden meer geoefend. Niettemin is het ondanks de grondige herziening van het coassistentschap nog niet gelukt de algemene eindtermen die betrekking hebben op de sociale geneeskunde voldoende aan de orde te laten komen. De korte duur en de takgerichte praktijkstage zijn hier waarschijnlijk debet aan. Dit betekent dat naar andere wegen gezocht moet worden om deze eindtermen alsnog te realiseren. Eén van de mogelijkheden is in de vorm van multidisciplinaire terugkomdagen (SOO), waarin reeds 'beroepsziekten' en 'forensische geneeskunde' aan de orde komen. ${ }^{8}$ De eerste evaluatieresultaten hiervan zijn zeer positief. Een onderwijsprogramma 'gezondheid en recht' wordt thans voorbereid. De eindterm 'aangifteplicht besmettelijke ziekten' is recent expliciet opgenomen in de introductie van het co-assistentschap. Het is derhalve de verwachting dat de betrokken eindtermen alsnog deels aan de orde kunnen komen. Nader onderzoek zal echter moeten uitwijzen of dit werkelijk gebeurt. Ten slotte is in 1999 het Nederlands leerboek 'Volksgezondheid en Gezondheidszorg', dat bij de meeste faculteiten als leerboek sociale geneeskunde wordt gebruikt, geheel herzien, inclusief de leerstof die betrekking heeft op de eindterm 'structuur en functioneren van de gezondheidszorg'. 9 Wellicht kunnen over enkele jaren de vruchten hiervan in de co-assistentschappen worden geplukt.

In het co-assistentschap sociale geneeskunde komt circa de helft van de sociaalgeneeskundige problemen aan de orde. 
Ook hier moet naar een oplossing gezocht worden. Een betere roostering van de praktijkstages over de verschillende sociaal-geneeskundige takken en de hiermee samenhangende eindpresentaties kan hierbij behulpzaam zijn. Het aantal presentaties per groep is echter beperkt: uit ervaring blijkt een aantal van acht ideaal te zijn. Door een uitbreiding van praktijkstages in de thuiszorg (ouder en kindzorg) vormen problemen die samenhangen met de zorg voor 0-4 jarigen (onder andere voeding, groei en ontwikkeling) een expliciet onderdeel van het herziene co-assistentschap sociale geneeskunde. Ten slotte zal ook hier naar onderwijsalternatieven gezocht moeten worden, bijvoorbeeld in het SOO. Het probleem 'eczemen' komt bijvoorbeeld in het SOO 'beroepsziekten' expliciet aan de orde.

De sociaal-geneeskundige vaardigheden komen in het herziene co-assistentschap expliciet aan de orde en worden in voldoende mate geoefend.

De verkregen gegevens betreffen het VUmc. Omdat de diensten en instellingen waarmee wordt samengewerkt landelijk niet wezenlijk verschillen, kan verwacht worden dat ook elders het aanbod van sociaal-geneeskundige problemen niet erg hiervan zal afwijken.

De wijze waarop co-assistenten worden geconfronteerd met problemen en zich bekwaam achten ten aanzien van bepaalde eindtermen en vaardigheden is vooral afhankelijk van de invulling van het co-assistentschap. Daadwerkelijk oefenen in een praktische setting, zoals in het co-assistentschap sociale geneeskunde, blijft essentieel voor alle aanstaande artsen.

\section{Literatuur}

1. Metz JCM, Pels Rijcken-Van Erp Taalman Kip EH, Brand-Valkenburg BWM van den. Raamplan 1994 artsopleiding, eindtermen van de artsopleiding. Nijmegen: Universitair Publikatiebureau Katholieke Universiteit Nijmegen; 1994.
2. Soethout MBM, Verweij AMJJ, Tilburg W van. Algemene eindtermen van het Raamplan 1994 in de co-assistentschappen van de Vrije Universiteit. In: Verweij AMJJ, Albersnagel ED, Cate ThJ ten, Denekens J, Dikkers JH, Remmen R et al., redactie. Gezond Onderwijs - 7. Houten/Diegem: Bohn Stafleu Van Loghum; 1998. p. 279-281.

3. Vries H de, Donker AJM. Problemenlijst en disciplinegebonden eindtermen van het Raamplan 1994 geoperationaliseerd. In: Spaai GWG, Verweij AMJJ, Remmen R, Dolmans DHJM, Denekens JPM, Smal JA et al., redactie. Gezond Onderwijs - 8. Houten/Diegem: Bohn Stafleu Van Loghum; 1999. p. 329-332.

4. De vorming van de arts; een gestructureerd leerproces. Eindrapport van de Commissie Inrichting Co-assistentschappen. Amsterdam: Bureau Faculteit der Geneeskunde VU; 1998.

5. Hem-Stokroos HH van der, Daelmans HEM. Ontwikkeling van een logboek ten behoeve van co-assistentschappen. In: Spaai GWG, Verweij AMJJ, Remmen R, Dolmans DHJM, Denekens JPM, Smal JA et al., redactie. Gezond Onderwijs - 8. Houten/Diegem: Bohn Stafleu Van Loghum; 1999. p. 369-371.

6. Daelmans HEM, Thijs A, Hem-Stokroos HH van der, Vries H de, Donker AJM. Algemene eindtermen in onderwijs, beoordeling en toetsing gedurende enkele co-assistentschappen. In: Spaai GWG, Verweij AMJJ, Remmen R, Dolmans DHJM, Denekens JPM, Smal JA et al., redactie. Gezond Onderwijs - 8. Houten/Diegem: Bohn Stafleu Van Loghum; 1999. p. 126-129.

7. Klein Ikkink AJ, Vries $H$ de, Verweij AMJJ, Soethout MBM, Hem-Stokroos HH van der. Patiëntencontacten in de co-assistentschappen. In: Spaai GWG, Verweij AMJJ, Remmen R, Dolmans DHJM, Denekens JPM, Smal JA et al., redactie. Gezond Onderwijs - 8. Houten/Diegem: Bohn Stafleu Van Loghum; 1999. p. 204-209.

8. Reijnders UJL, Das C, Soethout MBM, Wal G van der. Artsen herkennen niet-natuurlijke dood onvoldoende, (bij)scholing in de forensische geneeskunde moet worden verplicht. Medisch Contact 1999;49:1704-21.

9. Maas PJ van der, Mackenbach JP, redactie. Volksgezondheid en Gezondheidszorg. Utrecht: Elsevier Bunge; 1999. 
De auteurs:

Drs. M.B.M. Soethout, arts maatschappij en gezondheid, onderwijscoördinator Sociale Geneeskunde, $V U$ medisch centrum, Amsterdam.

Prof. dr. G. van der Wal, hoogleraar Sociale Geneeskunde, $V U$ medisch centrum, Amsterdam.

Prof. dr. W. van Mechelen, hoogleraar Sociale Geneeskunde i.h.b. de bedrijfsgezondheidszorg, VU medisch centrum, Amsterdam.

\section{Correspondentieadres:}

Drs. M.B.M. Soethout, Afdeling Sociale Geneeskunde, VU medisch centrum, Van der Boechorststraat 7, 1081 BT Amsterdam, tel: 020-4448384, mbm.soethout.social @med.vu.nl.

\section{Summary}

Introduction: In January 2000 a revised clerkship Public Health was introduced at the VU Medical Center Amsterdam. The objectives of undergraduate medical education in the Netherlands (Blueprint 1994) formed the basis of the revision. The new clerkship lasts two weeks and is scheduled at the end of the undergraduate medical curriculum (sixth year).

Methods: At the end of the old three-week clerkship in 1999 and at the end of the new two-week clerkship in 2000 students were asked to which extent they had mastered Blueprint objectives in Public Health. They were also asked whether they had practised public health skills, such as 'giving advice and health education for individuals or groups'. Results: Knowledge objectives and skills appear to be mastered at a higher level at the end of the new clerkship.

Conclusion: Explicit focussing on the knowledge and skills objectives from Blueprint 1994 can be realised by revision of the educational programme and can lead to improved attainment of these objectives, even with a shorter clerkship. (Soethout MBM, Wal G van der, Mechelen W van. Attainment of knowledge and skill objectives in the Public Health clerkship at the Amsterdam VU Medical Center. Dutch Journal of Medical Education 2001;20(6):248-256.) 